\title{
Statistical regression modeling and machinability study of hardened AISI 52100 steel using cemented carbide insert
}

\author{
Amlana Panda, Ashok Kumar Sahoo* and Arun Kumar Rout
}

School of Mechanical Engineering, KIIT University, Bhubaneswar-24, Odisha, India

\begin{tabular}{l}
\hline C H R O N I C L E \\
\hline Article history: \\
Received Februray 42016 \\
Received in Revised Format \\
June 162016 \\
Accepted July 122016 \\
Available online \\
July 162016 \\
\hline Keywords: \\
Hard turning \\
Machinability \\
Cemented carbide \\
Flank wear \\
Surface roughness \\
Regression
\end{tabular}

\section{Introduction}

Machining of hardened steel is becoming now an emerging technology due to high flexibility, high productivity, and reduction of cycle time, higher productivity and being utilized under dry cutting conditions. It is widely now-a-days applied in manufacturing industry and concerned about the finishing of hardened materials above $45 \mathrm{HRC}$. For successful implementation of hard turning, tool materials like cubic boron nitride $(\mathrm{CBN})$ and ceramics are used in operation. However with the advent of advanced cutting inserts and rigid machining systems, turning of workpiece below $45 \mathrm{HRC}$ is treated now-a-days as soft turning and in between 45-65 HRC, it is referred as hard turning. As different variables like cutting speed, feed and depth of cut, geometrical parameters (nose radius, rake angle, edge geometry), hardness, cutting tool vibrations and environmental parameters like cutting fluids affects the machinability performance in hard turning, the research in this field is continuing for its successful implementation in the industry. Aerospace and automobile industries produces components and machining plays key role of it for fine surface finish which obviously deteriorates with the evolution of tool wear. Therefore the

* Corresponding author.

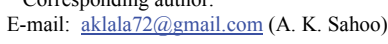

(C) 2017 Growing Science Ltd. All rights reserved. doi: $10.5267 /$ j. ijiec.2016.7.004

\begin{abstract}
The present study investigates performance and feasibility of application of low cost cemented carbide insert in dry machining of AISI 52100 steel hardened to $(55 \pm 1 \mathrm{HRC})$ which is rarely researched as far as machining of bearing steel is concerned. Machinability studies i.e. flank regression modeling has been developed. The test has been conducted based on Taguchi $\mathrm{L}_{16} \mathrm{OA}$ taking machining parameters like cutting speed, feed and depth of cut. It is observed that uncoated cemented carbide insert performs well at some selected runs (Run 1,5 and 9) which blue colour adversely affects the surface quality. Adequacy of the developed statistical regression model has been checked using ANOVA analysis (depending on $\mathrm{F}$ value, $\mathrm{P}$ value and $\mathrm{R}^{2}$ value) and normal probability plot at $95 \%$ confidence level. The results of optimal parametric combinations may be adopted while turning hardened AISI 52100 steel under dry environment with uncoated cemented carbide insert.
\end{abstract}


study of machinability is essentially needed and a brief literature review is presented with the various works performed by the researchers.

\section{Literature review}

Chen (2000) investigated the machining of hardened steel (45-55 HRC) using CBN insert. It is observed that the thrust force is higher compared to cutting force component. The surface finish is found to be close to the grinding process. The surface finish is influenced by variables like cutting speed, tool wear and plastic behaviour of the work material using CBN insert in operation. Davim and Figueira (2007) studied the machinability of D2 $(60 \mathrm{HRC})$ steel. The surface roughness less than 0.8 microns can be obtained with the suitable selection of parameters. This concludes that the hard turning can successively replace the traditional grinding operations. Sahin and Motorcu (2008) utilized the response surface methodology for hard turning of AISI 1050 steel using cubic boron nitride (CBN) cutting inserts under different conditions and developed model for surface roughness. Feed rate is found to be most influencing parameters for surface roughness. Singh and Rao (2007) studied turning of hardened AISI 52100 steel using mixed ceramic insert. The influence of cutting conditions and tool geometry has been investigated on surface roughness. Feed rate is found to be the most affecting parameter for surface finish and next parameter is nose radius and lastly cutting speed. Bouacha et al. (2010) studied tool wear and force behavior on machining hardened AISI 52100 steel (64 HRC) with CBN insert and developed model through response surface methodology. Thrust force components is found to be largest and parameters like depth of cut influences more on it compared to cutting speed and feed rate.

Guddat et al. (2011) investigated on hard turning of AISI 52100 (100Cr6) (58-62 HRC) steel using wiper PCBN inserts. The influence on surface integrity and cutting forces has been studied and developed a statistical model for cutting forces and surface roughness. Azizi et al. (2012) studied the influence of cutting parameters and workpiece hardness on surface roughness and cutting force during turning hardened AISI 52100 steel with coated $\mathrm{Al}_{2} \mathrm{O}_{3}+\mathrm{TiC}$ mixed ceramic cutting tools. The contributing effect of surface roughness is found to be feed rate, workpiece hardness and cutting speed. Similarly, the significant effect on cutting force components are obtained to be depth of cut; workpiece hardness and feed rate respectively. Zahia et al. (2015) studied on hard turning of AISI 4140 (56 HRC) steel using PVD coated ceramic insert. Feed rate and depth of cut are found to be the most significant parameters affecting surface roughness and cutting forces from analysis of variance (ANOVA) study. Chinchanikar et al. (2014) investigated during turning hardened AISI52100 steel (60-62HRC) using PVD-coated nano laminated TiSiN-TiAlN carbide tool taking various cooling medium and parameters on surface roughness. It is observed that under dry condition, lower surface roughness is obtained. At higher cutting speed, application of coconut oil lowers surface roughness values. It is more effective at higher feed and depth of cut also. Singh and Rao (2010) studied hard turning using ceramic insert and developed model for flank wear. It is observed that during progression of flank wear, normal load/force occurred at the flank face of the tool is found to be constant. Huang and Dawson (2005) studied and developed the model for crater wear depth in hard turning of AISI 52100 steel incorporating abrasion, adhesion and diffusion wear mechanisms and experimentally validated. Dureja (2012) presented a response surface model for flank and crater wear during hard turning of AISI-H11 steel with TiN coated CBN tool. It is evident that the cutting speed and feed have the significant effect on flank wear. Mandal et al. (2011) studied some aspects of machinability of AISI4340 steel using Zirconia Toughened Alumina (ZTA) ceramic inserts with respect to flank wear. The investigation revealed that depth of cut dominated flank wear to a greater extent followed by cutting speed. Sahoo and Sahoo (2012) experimentally investigated machining performance of hardened AISI 4340 steel (47HRC) applying uncoated and multilayer coated carbide inserts. Multilayer TiN outer layer coated carbide inserts performs well in comparison to uncoated and outer $\mathrm{ZrCN}$ coated carbide inserts. Sahu et al. (2015) experimentally investigated dry machining performance of hardened AISI 1015 (43 HRC) steel using carbide insert and compared under environment of spray cooling. It is better to adopt spray cooling environment than dry cutting conditions as machining performance improves significantly. Sahoo et al. (2013) developed prediction model for 
flank wear during dry hard turning of EN 24 steel with PVD TiN coated mixed ceramic insert. The principal wear mechanism during hard turning is obtained to be abrasion and diffusion. Most influencing factor for flank wear is observed to be machining time from ANOVA study. Das et al. (2015) experimentally investigated during dry hard turning operation in context to surface roughness, flank wear and chip morphology with coated carbide and ceramic insert and developed the predicted model. For surface roughness, feed is obtained as the influencing parameter and dominant wear mechanism is shown as abrasion. Saw tooth chip at higher feed degrades the surface finish. Models are found to be significant and adequate. Sahoo and Sahoo (2013) investigated multi-response parametric optimization and modeling aspects through RSM and grey relational analysis along with economical feasibility in turning hardened steel using multilayer coated carbide insert. Sahoo and Mishra (2014) performed optimization and modeling studies in turning hardened steel through RSM and desirability analysis. RSM model has been found to be good degree of accuracy.

Mhamdi et al. (2013) conducted hard turning tests for D2 steel (62 HRC) with various cutting conditions and obtained chip formation mechanisms and optimal parametric results. Sahoo and Sahoo (2013) assessed progression of flank wear and tool life in dry turning of hardened AISI 4340 steel ( $47 \pm 1$ HRC) with $\mathrm{ZrCN}$ outer multilayer coated carbide inserts. The principal wear mechanism is obtained to be abrasion. Zhang et al. (2006) studied the surface integrity aspects during turning hardened bearing steel (62-63 HRC) using CBN insert. The process generates appropriate cutting parameters for surface integrity. Feed rate has been found to be the dominant impact on the surface finish during study. Paiva et al. (2007) utilized TiN coated mixed ceramic tool during hard turning of AISI 52100 steel and studied the effect of cutting parameters. Cutting speed of $238 \mathrm{~m} / \mathrm{min}$, feed rate of $0.08 \mathrm{~mm} / \mathrm{rev}$ and depth of cut of $0.32 \mathrm{~mm}$ yields maximum material removal rate (MRR) with good surface quality. Davim and Figueira (2007) compared the performance of utilizing wiper and conventional ceramic inserts in turning hardened D2 steel (60 HRC). For flank wear, factors such as cutting time and cutting velocity affects more. Feed rate affects more on specific cutting pressures of inserts. Wiper ceramic insert produced less than 0.8 microns of surface roughness during machining. It is revealed from literature review that tool wear affects more on quality of workpiece and also accuracy of dimensions of product. Most of study of hard turning is based on using CBN and ceramic inserts and subsequently models have been developed. Some studies have undertaken for medium hardened steel using coated carbide insert. Hard turning of AISI 52100 steel of hardness range of $55 \mathrm{HRC}$ or more has been investigated using costly CBN and ceramic insert which has found itself wide application in the bearing industry and can successfully replace the traditional grinding process. However the study on some machinability aspects during machining hardened AISI 52100 steel at higher hardness level around 55-60 HRC using cemented carbide insert is lacking from the review of literature and research is essentially needed for the wide application of carbide inserts in hard machining. This also may lead to an economic alternative to the tool already adopted during hard machining. Therefore, some machinability study and modeling and optimization study for the tool wear and surface roughness in machining hardened AISI 52100 steel using cemented carbide insert is extremely valuable.

In this framework, the present study is focused on some machinability study of AISI 52100 steel ( $55 \pm 1$ HRC) using uncoated cemented carbide insert under dry conditions using Taguchi $\mathrm{L}_{16}$ orthogonal array in context to responses such as flank wear, surface roughness and analyzing chip samples. Also, the parametric influences on responses are analyzed through ANOVA study and prediction models have also been presented through quadratic regression analysis. The optimized cutting parameters have also been suggested.

\section{Experimental procedure}

The selected material for test specimen are hardened AISI 52100 steel ( $55 \pm 1$ HRC) popularly used as bearing steel. This has taken in the shape of cylindrical rods of $40 \mathrm{~mm}$ diameter and length of $120 \mathrm{~mm}$. The hard turning experiments are conducted on a CNC lathe of $3500 \mathrm{rpm}$ spindle speed (maximum) and 
$16 \mathrm{KW}$ power with controller of sinumeric under dry environment (Fig. 1). The material for the cutting tool insert is commercially available uncoated cemented carbide diamond shape of CNMG 120408 type. The insert is mounted on a PCLNR2525 M12 type right hand tool holder. The levels of three cutting parameters (depth of cut, feed and cutting speed) are shown in Table 1. As per Taguchi $\mathrm{L}_{16}$ orthogonal array design, sixteen experiments are performed which is shown in Table 2 (Roy, 2001). For each experimental run, fresh cutting edge was used. With the help of surface roughness tester (Taylor Hobson, Surtronic 25) of cutoff length and assessment length of $0.8 \mathrm{~mm}$ and $4 \mathrm{~mm}$ and Nikon profile projector, responses i.e. arithmetic average surface roughness $(\mathrm{Ra})$ and flank wear $(\mathrm{VBc})$ for every run are measured and captured the images by Stereo zoom microscope. As the depth of cut chosen $(0.1-0.4 \mathrm{~mm})$ is smaller than nose radius $(0.8 \mathrm{~mm})$, flank wear occurred at the corner of nose radius $(\mathrm{VBc})$ and measured. The calibration of surface roughness tester was done before start of the measurements. The readings were obtained at four different surfaces of work surfaces and repeated two times at each location and average values are taken. Chips are collected at every runs. Control limit for surface roughness (Ra) and maximum flank wear land has been set as 1.6 microns and $0.6 \mathrm{~mm}$ respectively for machining with uncoated cemented carbide insert.

Table 1

Machining parameters and levels.

\begin{tabular}{ccccccc}
\hline Parameters & Notation & \multirow{2}{*}{ Unit } & \multicolumn{4}{c}{ Levels of factors } \\
\cline { 4 - 7 } & & & Level 1 & Level 2 & Level 3 & Level 4 \\
\hline Depth of cut & $\mathrm{d}$ & $\mathrm{mm}$ & 0.1 & 0.2 & 0.3 & 0.4 \\
feed & $\mathrm{f}$ & $\mathrm{mm} / \mathrm{rev}$ & 0.04 & 0.08 & 0.12 & 0.16 \\
Cutting speed & $\mathrm{v}$ & $\mathrm{m} / \mathrm{min}$ & 70 & 110 & 150 & 190 \\
\hline
\end{tabular}

Table 2

Taguchi $\mathrm{L}_{16}$ orthogonal array design

\begin{tabular}{cccccccc}
\hline Run & d & f & v & Run & d & f & v \\
\hline 1 & 1 & 1 & 1 & 9 & 3 & 1 & 3 \\
2 & 1 & 2 & 2 & 10 & 3 & 2 & 4 \\
3 & 1 & 3 & 3 & 11 & 3 & 3 & 1 \\
4 & 1 & 4 & 4 & 12 & 3 & 4 & 2 \\
5 & 2 & 1 & 2 & 13 & 4 & 1 & 4 \\
6 & 2 & 2 & 1 & 14 & 4 & 2 & 3 \\
7 & 2 & 3 & 4 & 15 & 4 & 3 & 2 \\
8 & 2 & 4 & 3 & 16 & 4 & 4 & 1 \\
\hline
\end{tabular}

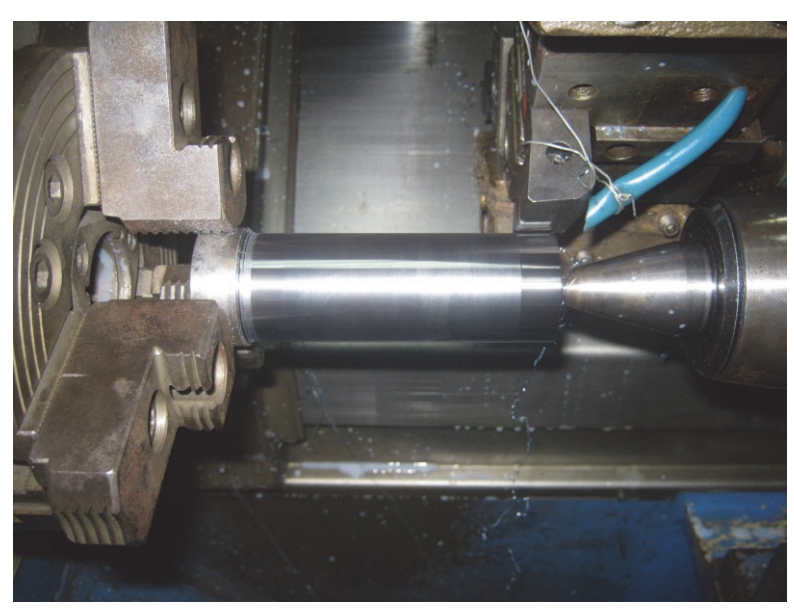

Fig. 1. Experimental setup 


\section{Results \& discussion}

The experimental results and images of inserts at each run are shown in Table 3 and Fig. 2, respectively.

Table 3

Test results of $\mathrm{VBc}$ and $\mathrm{Ra}$

\begin{tabular}{cccccc}
\hline Run No & \multicolumn{3}{c}{ Cutting parameters } & \multicolumn{2}{c}{ Experimental results } \\
\cline { 2 - 6 } & $\mathrm{d}$ & $\mathrm{f}$ & $\mathrm{V}$ & $\mathrm{VBc}$ & $\mathrm{Ra}$ \\
\hline 1 & 0.1 & 0.04 & 70 & 0.218 & 1.28 \\
2 & 0.1 & 0.08 & 110 & 0.706 & 2.23 \\
3 & 0.1 & 0.12 & 150 & 0.717 & 2.28 \\
4 & 0.1 & 0.16 & 190 & 1.178 & 2.98 \\
5 & 0.2 & 0.04 & 70 & 0.220 & 2.17 \\
6 & 0.2 & 0.08 & 190 & 0.745 & 2.82 \\
7 & 0.2 & 0.12 & 150 & 1.810 & 2.92 \\
8 & 0.2 & 0.16 & 150 & 1.117 & 1.61 \\
1 & 0.3 & 0.04 & 190 & 0.434 & 2.74 \\
10 & 0.3 & 0.08 & 1.488 & 2.44 \\
11 & 0.3 & 0.12 & 110 & 0.702 & 2.55 \\
13 & 0.3 & 0.16 & 190 & 1.027 & 2.79 \\
14 & 0.4 & 0.04 & 150 & 1.581 & 2.81 \\
15 & 0.4 & 0.08 & 110 & 1.552 & 2.87 \\
\hline
\end{tabular}

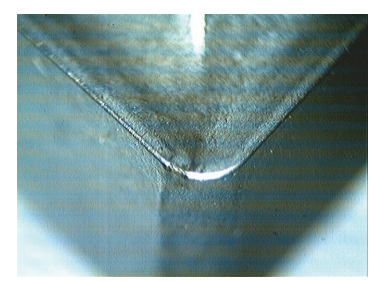

Run-1

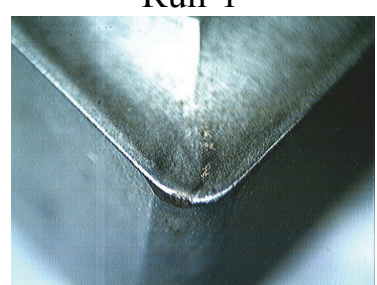

Run-5

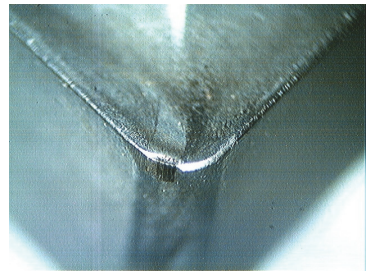

Run-9

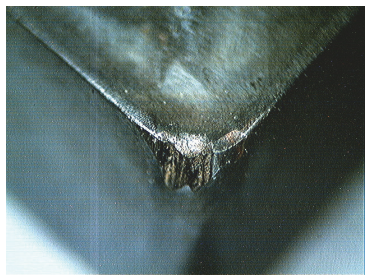

Run-13

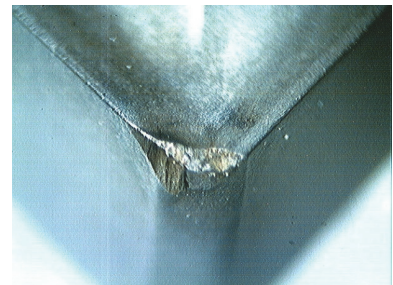

Run-2

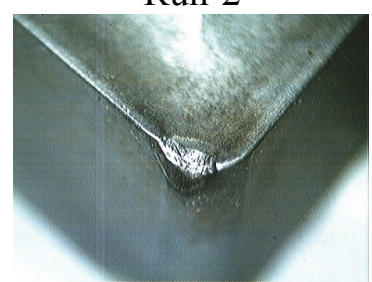

Run-6
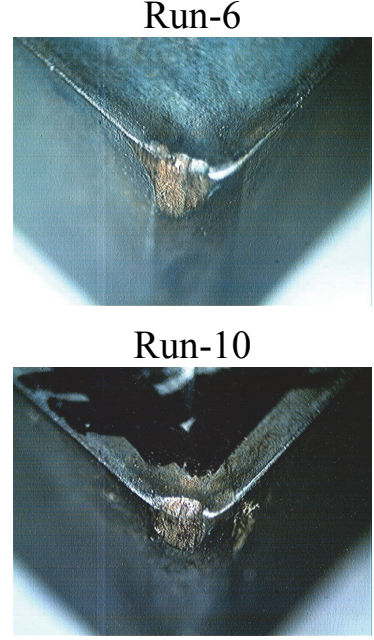

Run-14

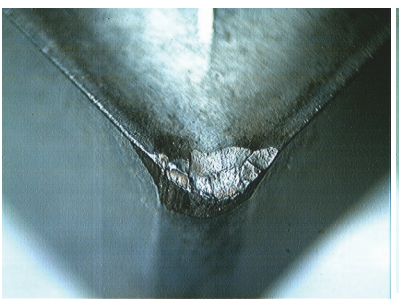

Run-3

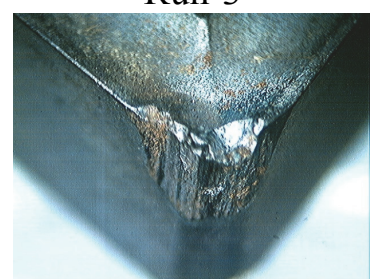

Run-7

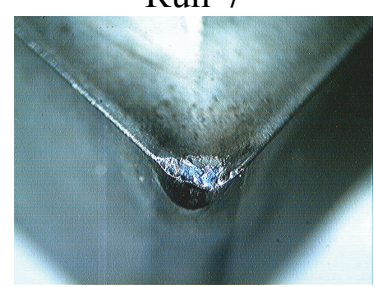

Run-11

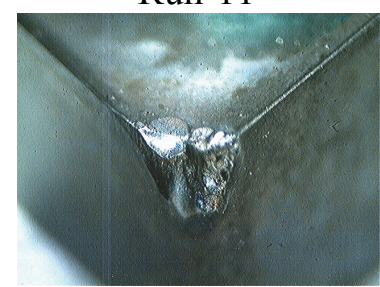

Run-15

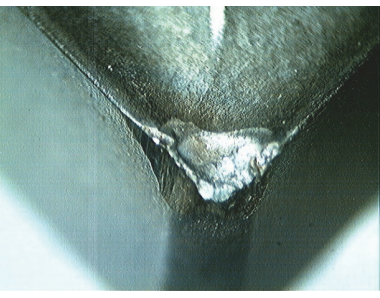

Run-4

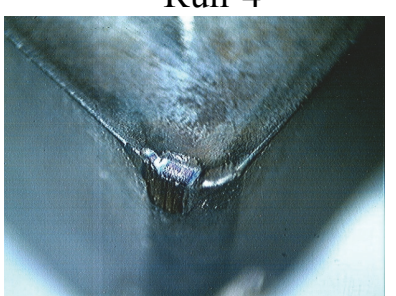

Run-8

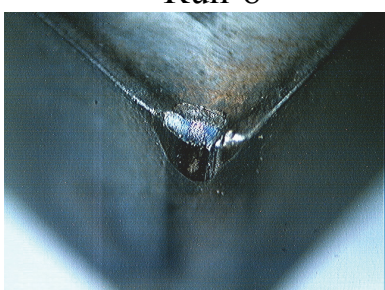

Run-12

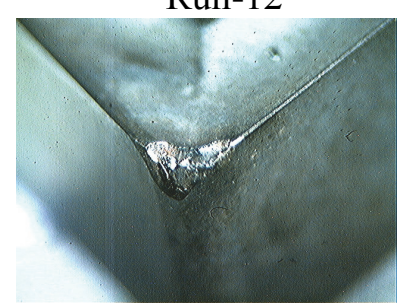

Run-16

Fig. 2. Flank wear images at different runs 


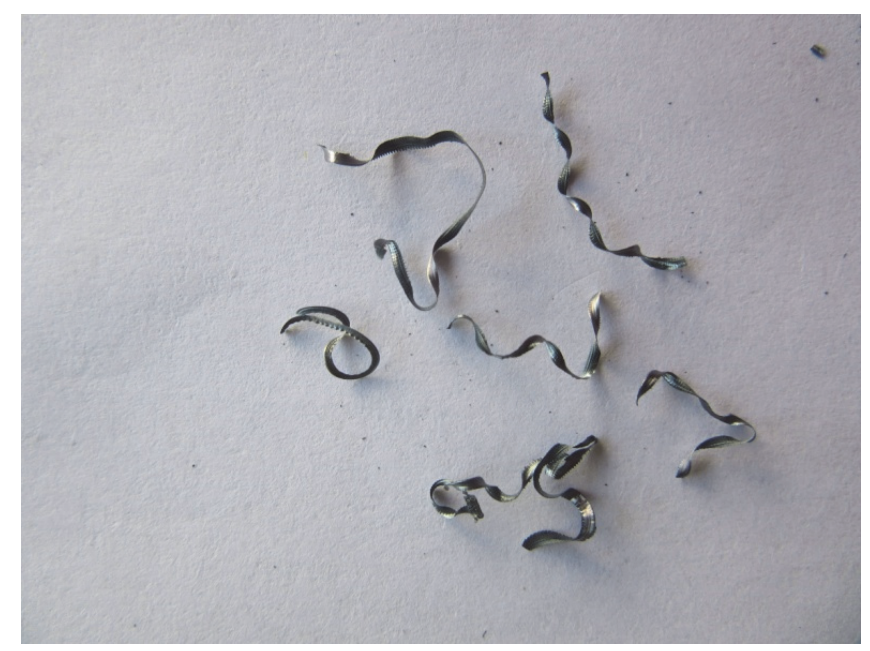

Fig. 3. Image of chips at Run $7(v=190 \mathrm{~m} / \mathrm{min}, \mathrm{f}=0.12 \mathrm{~mm} / \mathrm{rev}$ and $\mathrm{d}=0.2 \mathrm{~mm})$

\subsection{Analysis of experimental results}

From the chosen cutting parametric ranges, various wear mechanisms and modes of cutting tool failure were found and seen during experimentation. With continuous rubbing, some elements of cutting tools are removed away and attrition mechanisms are observed. It is observed that uncoated carbide inserts suffered from excessive flank wear at lower cutting speeds, higher feed-depth of cut cutting conditions (Run 6, 11 and 16). Failure of tool tip, abrasive scars at flank surface, adhesion of metal and deformation of cutting edge and chipping is clearly observed from the captured figures of worn out inserts (Fig. 2). Catastrophic failure of the cutting edge was seen and probably owing to mechanical fatigue (Run 7 and 10). Accelerated wear at flank face is observed for uncoated carbide insert which is due to lack of hot hardness property. Thus, the uncoated carbide insert failed to perform due to accelerated tool wear by abrasion, cutting edge dulling due to plastic deformation under stress and cutting temperature in most of the runs except Run 1, 5 and 9. Severe chipping at the cutting edge was seen particularly in run 7, 10, 13, 14 and 15 respectively.

The tool tip fracture is clearly noticed and this may be because of high shear stresses generated by the sudden rise of temperature gradient for uncoated carbide insert during machining hardened AISI 52100 steel. At higher cutting speed and feed rate, cutting edges undergo plastic deformation as hardness of cutting insert reduces with rise in cutting speed. Thus chipping is the primary source of cutting tool failure noticed in the studied range and probably because of inadequate strength to sustain high stress at elevated parametric conditions. From the experiment, it is observed that for a flank wear $(\mathrm{VBc})$ upto $0.6 \mathrm{~mm}$, the corresponding arithmetic surface roughness averages (Ra) are within 1.6 microns. When flank wear exceeds $0.6 \mathrm{~mm}$, surface roughness increases. The analysis reveals that surface roughness is dependent on the flank wear closely. That means evolution of flank wear degrades the surface quality. Serrated saw tooth chips with burnt blue colour are obtained in majority of runs when machining with uncoated carbide insert (Fig. 3). This reveals the higher cutting temperature induced during machining that leads to failure of sharp edge of cutting tool and consequently degrades the surface quality. It is evident from experimental results that the uncoated carbide did not perform well for machining operation as it crosses criteria wear limit of $0.6 \mathrm{~mm}$ except Run-1, 5 and 9 only. Chipping or fracturing of cutting edges are not observed in Run-1, 5 and 9 respectively and machining was steady. It is clear from the experimental findings that the arithmetic surface roughness average obtained by uncoated carbide insert has lower value i.e. less than or approaches to 1.6 microns for Run 1, 5 and 9 respectively. For all other runs, it exceeds the surface roughness of 1.6 microns. The main effect plot is constructed to reveal the influence of cutting parameters on responses. From the figure of main effect plot (Fig. 4 and Fig. 5), flank wear and surface roughness increases as the cutting parameters increases. With the rise of cutting speed, cutting temperature at the contact zone increases. This may cross the limit of thermal stability of the 
uncoated carbide insert used in the machining by virtue of which flank wear increases drastically. Also at higher cutting speed, the rubbing between the flank and workpiece occurs vary faster rate and significant increase of temperature evolved at minimum contact time. Thus cutting edge softens to a larger extent due to rise of cutting temperature and accelerates the flank wear (Suresh et al., 2012). Again from interaction plot (Fig. 6 and Fig. 7), feed-cutting speed has significance on flank wear and Interaction effect of feed-depth of cut; feed-cutting speed and cutting speed-depth of cut have been found to be very significant on surface roughness. The surface roughness sharply increases with the feed. As the thrust force increases due to rise of feed in hard machining which is observed by Gaitonde et al. (2009) and Suresh et al. (2012) in his experimentation, vibration of machine tool becomes more predominant that leads to failure of cutting edge and responsible for degradation of surface quality.

From analysis of variance (ANOVA), feed is found to be the most significant factor for flank wear followed by cutting speed as its P-value is less than 0.05 at $95 \%$ confidence level (Montgomery, 2000) which is shown in Table 4 and 5 respectively. Similarly, feed plays a major role for surface roughness followed by cutting speed and depth of cut. From the above findings, it is evident that the uncoated carbide insert performs well at run 1,5 and 9 respectively which indicates its potential at higher cutting speed range from $70 \mathrm{~m} / \mathrm{min}$ to $150 \mathrm{~m} / \mathrm{min}$ but at lower feed range only $(0.04 \mathrm{~mm} / \mathrm{rev})$. At Run 1,5 and 9 , the flank wear and surface roughness values are well within the recommended range of $\mathrm{VBc}=0.6 \mathrm{~mm}$ and $\mathrm{Ra}=1.6$ microns which shows its feasibility for hard turning applications. Therefore there is need to improve the performance of uncoated carbide insert so as to be suitable for hard turning applications. Thus, the optimized process parameters and prediction model for responses are essentially required for its effective application which has been described in subsequent sections.

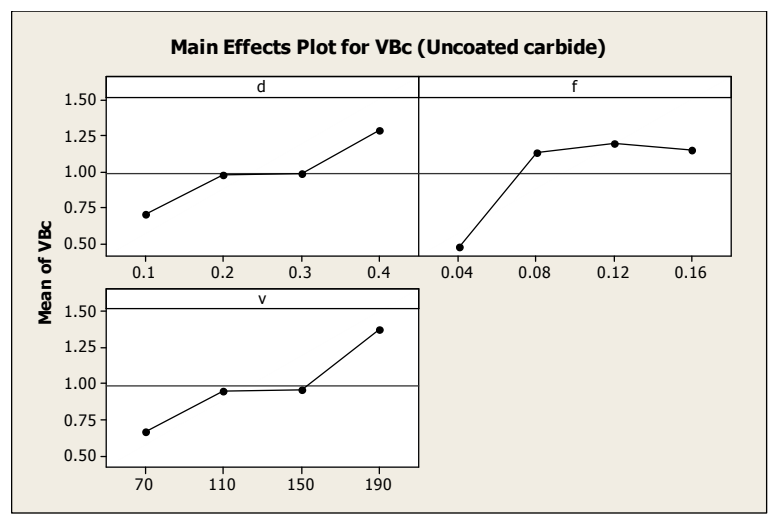

Fig. 4. Main effects plot for $\mathrm{VBc}$

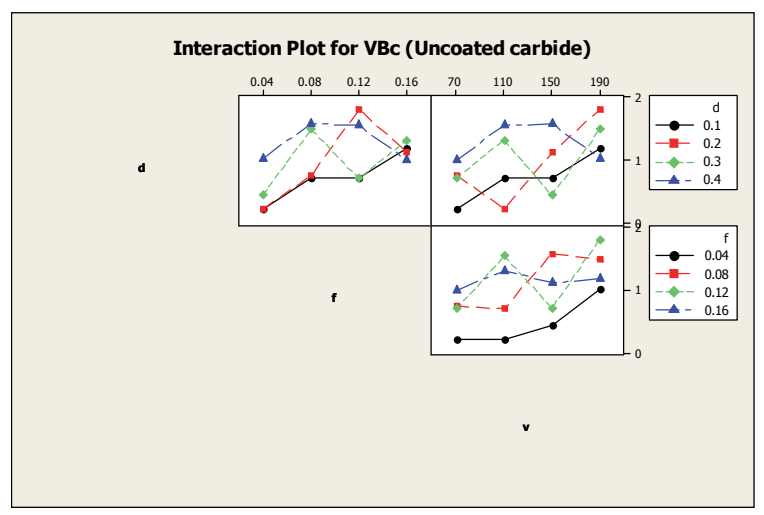

Fig. 6. Interaction plot for VBc

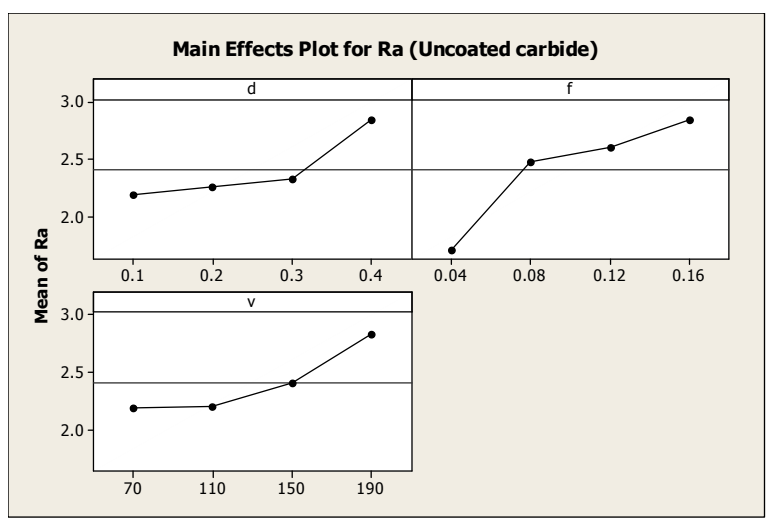

Fig. 5. Main effects plot for Ra

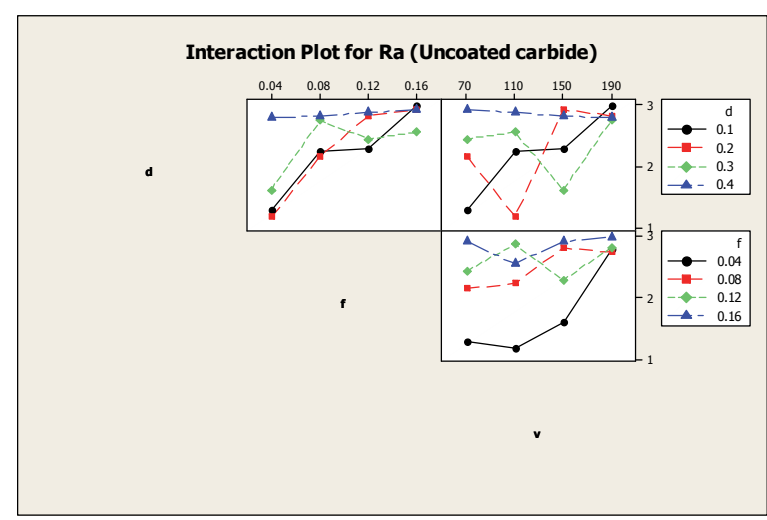

Fig. 7. Interaction plot for Ra 
Table 4

ANOVA for VBc

\begin{tabular}{ccccccc}
\hline Source & DF & SS & MS & F & P & Remarks \\
\hline d & 3 & 0.6824 & 0.2274 & 3.27 & 0.101 & Insignificant \\
f & 3 & 1.4131 & 0.471 & 6.76 & 0.024 & Significant \\
v & 3 & 1.0287 & 0.3429 & 4.92 & 0.047 & Significant \\
Error & 6 & 0.4177 & 0.0696 & & & \\
\hline Total & 15 & 3.542 & & & & \\
\hline
\end{tabular}

Table 5

ANOVA for Ra

\begin{tabular}{ccccccc}
\hline Source & DF & SS & MS & F & P & Remarks \\
\hline d & 3 & 1.0614 & 0.3538 & 8.77 & 0.013 & Significant \\
f & 3 & 2.8635 & 0.9545 & 23.65 & 0.001 & Significant \\
v & 3 & 1.0628 & 0.3542 & 8.78 & 0.013 & Significant \\
Error & 6 & 0.2422 & 0.0403 & & & \\
\hline Total & 15 & 5.23 & & & \\
\hline
\end{tabular}

\subsection{Development of mathematical model and optimization of cutting parameters}

The quadratic regression models for responses such as flank wear and surface roughness have been developed at a $95 \%$ confidence level taking the results of data obtained from experiment. The input variables or the predictors are responses i.e. depth of cut (d), feed (f) and cutting speed (v) respectively. The model is said to be statistically significance when the P-value (probability of significance) of its input parameters is found to be less than 0.05 . Determination coefficients $\left(\mathrm{R}^{2}\right)$ were evaluated for best fitting of prediction models and model is adequate and significant if higher $\mathrm{R}^{2}$ value is obtained. Similarly, the significance of models have been tested if P-value is less than 0.05 ( $95 \%$ confidence level).

The models are presented in Eqs. (1-2) as follows:

$$
\begin{aligned}
& V B c=0.791-4.4 d+9.723 f-0.014 v+0.862 d^{2}-109.219 f+0.00 v^{2}+31.977 d f+0.03 d v+0.093 f v \\
& \mathrm{R}^{2}=95.7 \%, \mathrm{R}^{2}(\operatorname{adj})=89.3 \% \\
& \mathrm{Ra}=1.6952-6.2182 \mathrm{~d}+33.4276 \mathrm{f}-0.0209 \mathrm{v}+11 \mathrm{~d}^{2}-82.8125 \mathrm{f}^{2}+0.0001 \mathrm{v}^{2}-16.6477 \mathrm{df}+0.0332 \mathrm{dv}-0.0072 \mathrm{fv} \\
& \mathrm{R}^{2}=96.1 \%, \mathrm{R}^{2}(\mathrm{adj})=90.2 \%
\end{aligned}
$$

The determination coefficient $\left(\mathrm{R}^{2}\right)$ values for both models of $\mathrm{VBc}$ and $\mathrm{Ra}$ are observed to be higher i.e. 0.957 and 0.961 (close to 1 ) explaining $95.7 \%$ and $96.1 \%$ of the variability in the responses. This shows high significance of the model statistically. It indicates good agreement and correlation between experimental values and predicted values and model is significant. Also, the adjusted $\mathrm{R}^{2}(89.3 \%$ and $90.2 \%$ ) value is approximately near to the predicted $\mathrm{R}^{2}$ that shows also the significance of the model. From the result of ANOVA model for flank wear and surface roughness (Table 6 and Table 7), it implies that the quadratic regression models are significant as the P-value is less than 0.05 . Normal probability plot of the residuals for the flank wear and surface roughness are plotted to test also the statistical validity. It shows that the residuals closely follow a straight line implying that the models are significant (Fig. 8 and Fig. 9). The structure less distributions of plot of residuals versus fitted values (Fig. 10 and Fig. 11) indicates models are adequate and significant. Thus, the developed quadratic regression models are sufficient enough to assess accurate prediction of responses in turning hardened AISI 52100 steel (55 \pm $1 \mathrm{HRC}$ ) using cemented carbide inserts. Furthermore, contour plots are plotted for prediction of responses at desired domain of experimentation. The contour plot of flank wear and surface roughness in different planes are shown in Fig. 12 and Fig. 13, respectively. Contour plots resembles with the curvilinear profile shape as per quadratic regression models. From the contour plots, optimal parametric combinations such as for low level of cutting speed $(70 \mathrm{~m} / \mathrm{min})$-feed $(0.04 \mathrm{~mm} / \mathrm{rev})$-depth of cut $(0.1 \mathrm{~mm})$ is obtained for lowering flank wear and surface roughness respectively. Thus this optimized parametric combination is 
suggested in reducing tool wear and surface roughness in hard turning of AISI 52100 steel ( $55 \pm 1$ HRC) under dry environment using cemented carbide insert. At optimized cutting conditions, the flank wear $(\mathrm{VBc})$ and surface roughness $(\mathrm{Ra})$ values are observed to be $0.218 \mathrm{~mm}$ and 1.28 microns respectively which is well within the recommended range and shows its feasibility in machining hardened steel.

Table 6

ANOVA for VBc model.

\begin{tabular}{cccccccc}
\hline Source & DF & Seq SS & Adj SS & Adj MS & F & P & Remarks \\
\hline Regression & 9 & 3.3902 & 3.3901 & 0.3766 & 14.88 & 0.002 & Significant \\
Linear & 3 & 2.4217 & 0.1681 & 0.056 & 2.21 & 0.187 & \\
Square & 3 & 0.5064 & 0.5064 & 0.1688 & 6.67 & 0.024 & \\
Interaction & 3 & 0.4619 & 0.4619 & 0.1539 & 6.08 & 0.03 & \\
Residual Error & 6 & 0.1518 & 0.1518 & 0.0253 & & & \\
\hline Total & 15 & 3.542 & & & & \\
\hline
\end{tabular}

Table 7

ANOVA for Ra model.

\begin{tabular}{cccccccc}
\hline Source & DF & Seq SS & Adj SS & Adj MS & F & P & Remarks \\
\hline Regression & 9 & 5.0246 & 5.0246 & 0.5582 & 16.31 & 0.001 & Significant \\
Linear & 3 & 4.1784 & 0.8111 & 0.2703 & 7.9 & 0.017 & \\
Square & 3 & 0.6509 & 0.6509 & 0.2169 & 6.34 & 0.027 & \\
Interaction & 3 & 0.1952 & 0.1952 & 0.065 & 1.9 & 0.231 & \\
Residual Error & 6 & 0.2054 & 0.2054 & 0.0342 & & & \\
\hline Total & 15 & 5.23 & & & &
\end{tabular}

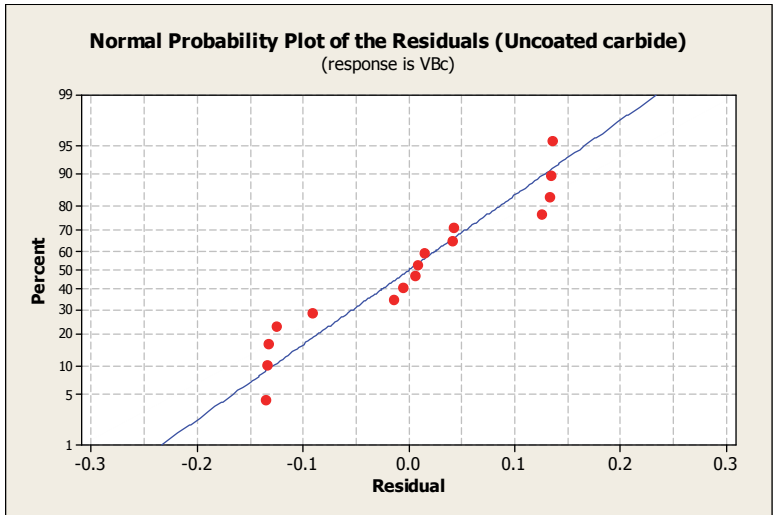

Fig. 8. Normal probability plot for flank wear

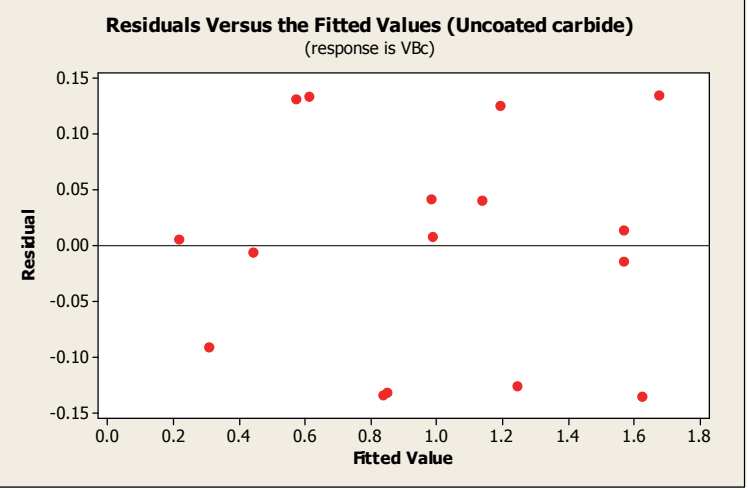

Fig. 10. Residuals vs. fitted values for flank wear

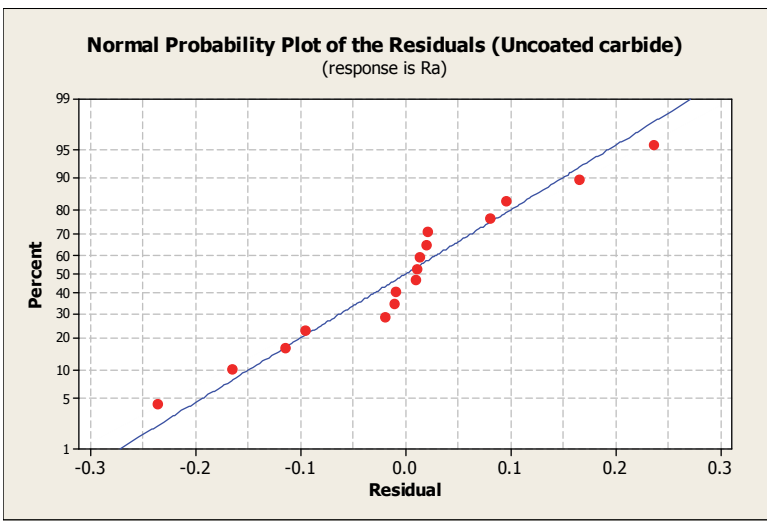

Fig. 9. Normal probability plot for surface roughness

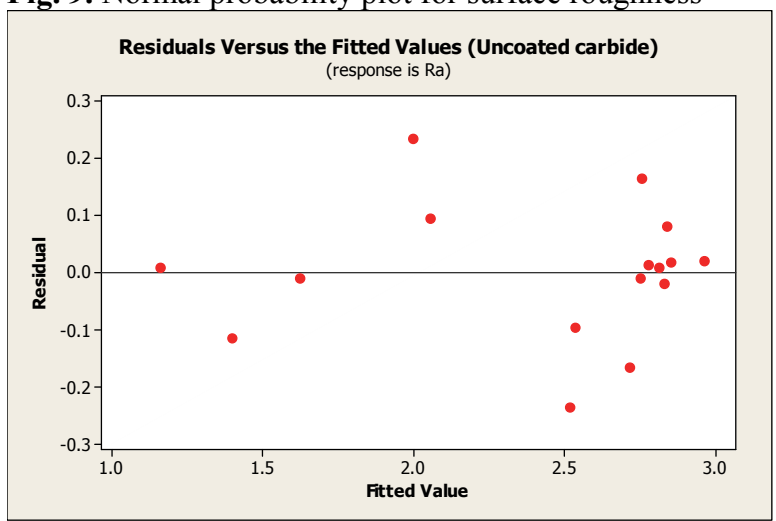

Fig. 11. Residuals vs. fitted values for surface roughness 


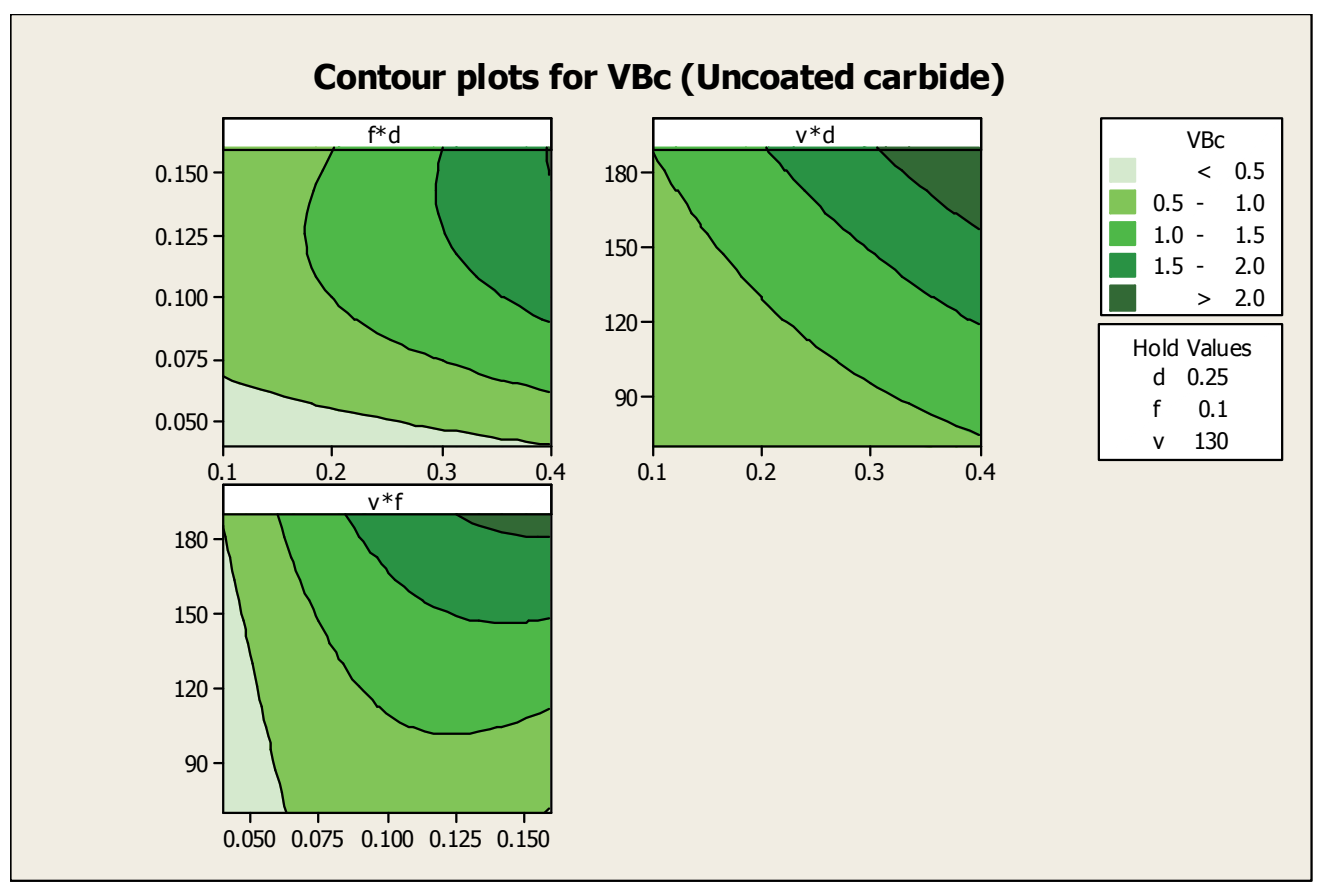

Fig. 12. Contour plots for flank wear (VBc)

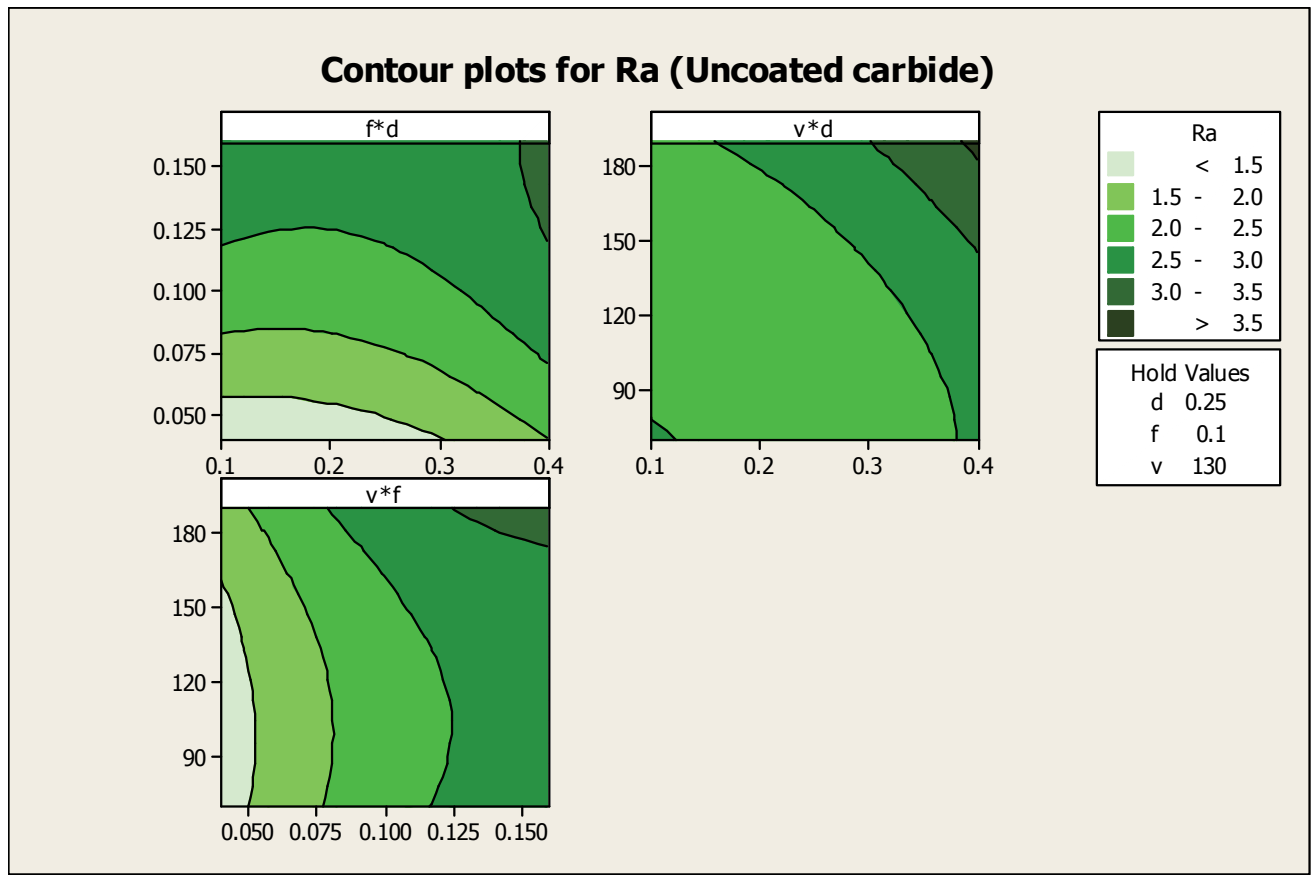

Fig. 13. Contour plots for surface roughness $(\mathrm{Ra})$

\section{Conclusions}

The feasibility of utilization of uncoated cemented carbide inserts in turning hardened AISI 52100 steel ( $55 \pm 1 \mathrm{HRC}$ ) has been investigated with respect to machinability and regression modeling study. Study revealed that abrasion and chipping was the dominant wear mechanisms in machining hardened steel. Failure of tool tip, abrasive scars, adhesion of metal and cutting edge deformation and catastrophic failure are seen from the captured images of worn out inserts resulting rapid tool wear. Progress of flank wear degrades the surface quality. 
However, uncoated cemented carbide insert performs well at run 1, 5 and 9 respectively which indicates its potential at higher cutting speed range from $70 \mathrm{~m} / \mathrm{min}$ to $150 \mathrm{~m} / \mathrm{min}$ but at lower feed range only $(0.04$ $\mathrm{mm} / \mathrm{rev}$ ) and flank wear and surface roughness values are well within the recommended range. This shows its feasibility for hard turning applications.

Prediction model developed using quadratic regression approach has been found to be statistically significant. Optimized parametric combinations such as cutting speed $(70 \mathrm{~m} / \mathrm{min})$, feed rate $(0.04$ $\mathrm{mm} / \mathrm{rev})$ and depth of cut $(0.1 \mathrm{~mm})$ have been obtained. At optimized parametric cutting conditions, flank wear of $0.218 \mathrm{~mm}$ and surface roughness of 1.28 microns are obtained which is well within the recommended range and may be considered in hard turning.

\section{Acknowledgements}

Authors are grateful to Central Tool Room \& Training Centre (CTTC) and KIIT University, Bhubaneswar, Odisha, India for extending their facilities to perform experimental and measurement works.

\section{References}

Azizi, M. W., Belhadi, S., Yallese, M. A., Mabrouki, T., \& Rigal, J. F. (2012). Surface roughness and cutting forces modeling for optimization of machining condition in finish hard turning of AISI 52100 steel. Journal of mechanical science and technology, 26(12), 4105-4114.

Bouacha, K., Yallese, M. A., Mabrouki, T., \& Rigal, J. F. (2010). Statistical analysis of surface roughness and cutting forces using response surface methodology in hard turning of AISI 52100 bearing steel with CBN tool.International Journal of Refractory Metals and Hard Materials, 28(3), 349-361.

Chen, W. (2000). Cutting forces and surface finish when machining medium hardness steel using CBN tools. International journal of machine tools and manufacture, 40(3), 455-466.

Chinchanikar, S., Salve, A. V., Netake, P., More, A., Kendre, S., \& Kumar, R. (2014). Comparative evaluations of surface roughness during hard turning under dry and with water-based and vegetable oil-based cutting fluids.Procedia Materials Science, 5, 1966-1975.

Das, S. R., Dhupal, D., \& Kumar, A. (2015). Experimental investigation into machinability of hardened AISI 4140 steel using TiN coated ceramic tool.Measurement, 62, 108-126.

Davim, J. P., \& Figueira, L. (2007). Machinability evaluation in hard turning of cold work tool steel (D2) with ceramic tools using statistical techniques.Materials \& design, 28(4), 1186-1191.

Davim, J. P., \& Figueira, L. (2007). Comparative evaluation of conventional and wiper ceramic tools on cutting forces, surface roughness, and tool wear in hard turning AISI D2 steel. Proceedings of the Institution of Mechanical Engineers, Part B: Journal of Engineering Manufacture, 221(4), 625-633.

Dureja, J. S. (2012). Optimisation of tool wear during hard turning of AISI-H11 steel using TiN coated CBN-L tool. International Journal of Machining and Machinability of Materials 2, 12(1-2), 37-53.

Huang, Y., \& Dawson, T. G. (2005). Tool crater wear depth modeling in CBN hard turning. Wear, 258(9), 1455-1461.

Guddat, J., M'Saoubi, R., Alm, P., \& Meyer, D. (2011). Hard turning of AISI 52100 using PCBN wiper geometry inserts and the resulting surface integrity.Procedia Engineering, 19, 118-124.

Gaitonde, V. N., Karnik, S. R., Figueira, L., \& Davim, J. P. (2009). Analysis of machinability during hard turning of cold work tool steel (type: AISI D2).Materials and Manufacturing Processes, 24(12), $1373-1382$.

Mandal, N., Doloi, B., Mondal, B., \& Das, R. (2011). Optimization of flank wear using Zirconia Toughened Alumina (ZTA) cutting tool: Taguchi method and Regression analysis. Measurement, 44(10), 2149-2155.

Mhamdi, M. B., Salem, S. B., Boujelbene, M., \& Bayraktar, E. (2013). Experimental study of the chip morphology in turning hardened AISI D2 steel. Journal of Mechanical Science and Technology, 27(11), 3451-3461. 
Montgomery, D.C., (2000). Design and analysis of experiments. John Wiley \& sons.

Paiva, A. P., Ferreira, J. R., \& Balestrassi, P. P. (2007). A multivariate hybrid approach applied to AISI 52100 hardened steel turning optimization. Journal of Materials Processing Technology, 189(1), 2635.

Roy, R.K. (2001). Design of Experiments using the Taguchi Approach: 16 Steps to Product and Process Improvement. John Wiley \& Sons, USA.

Sahin, Y. \& Motorcu, A.R. (2008). Surface roughness model in machining hardened steel with cubic boron nitride cutting tool. International Journal of Refractory Metals Hard Materials, 26(2), 84-90.

Sahoo, A.K., \& Sahoo, B. (2012). Experimental investigations on machinability aspects in finish hard turning of AISI4340 steel using uncoated and multilayer coated carbide inserts. Measurement, 45(8), 2153-2165.

Sahoo, A., Orra, K., \& Routra, B. (2013). Application of response surface methodology on investigating flank wear in machining hardened steel using PVD TiN coated mixed ceramic insert. International Journal of Industrial Engineering Computations, 4(4), 469-478.

Sahoo, A. K., \& Sahoo, B. (2013). Performance studies of multilayer hard surface coatings (TiN/TiCN/Al $2 \mathrm{O} 3 / \mathrm{TiN}$ ) of indexable carbide inserts in hard machining: Part-II (RSM, grey relational and techno economical approach).Measurement, 46(8), 2868-2884.

Sahoo, A. K., \& Mishra, P. C. (2014). A response surface methodology and desirability approach for predictive modeling and optimization of cutting temperature in machining hardened steel. International Journal of Industrial Engineering Computations, 5(3), 407.

Sahoo, A., \& Sahoo, B. (2013). Experimental investigation on flank wear and tool life, cost analysis and mathematical model in turning hardened steel using coated carbide inserts. International Journal of Industrial Engineering Computations, 4(4), 571-578.

Sahu, S.K., Mishra, P.C., Orra, K., Sahoo, A.K. (2015). Performance assessment in hard turning of AISI 1015 steel under spray impingement cooling and dry environment. Proceedings of the Institution of Mechanical Engineers, Part B: Journal of Engineering Manufacture, 229(2), 251-265.

Singh, D., \& Rao, P. V. (2007). A surface roughness prediction model for hard turning process. The International Journal of Advanced Manufacturing Technology, 32(11-12), 1115-1124.

Singh, D., \& Rao, P. V. (2010). Flank wear prediction of ceramic tools in hard turning. The International Journal of Advanced Manufacturing Technology,50(5-8), 479-493.

Suresh, R., Basavarajappa, S., \& Samuel, G. L. (2012). Some studies on hard turning of AISI 4340 steel using multilayer coated carbide tool.Measurement, 45(7), 1872-1884.

Zahia, H., Athmane, Y., Lakhdar, B., \& Tarek, M. (2015). On the application of response surface methodology for predicting and optimizing surface roughness and cutting forces in hard turning by PVD coated insert.International Journal of Industrial Engineering Computations, 6(2), 267-284.

Zhang, X., Liu, C. R., \& Yao, Z. (2007). Experimental study and evaluation methodology on hard surface integrity. The International Journal of Advanced Manufacturing Technology, 34(1-2), 141-148.

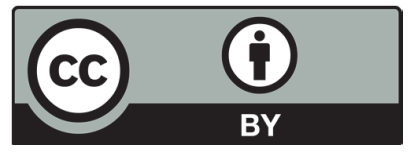

(C) 2016 by the authors; licensee Growing Science, Canada. This is an open access article distributed under the terms and conditions of the Creative Commons Attribution (CCBY) license (http://creativecommons.org/licenses/by/4.0/). 